\title{
Spectrum of CT in Paediatric Dengue with Respiratory Complaints
}

\author{
Veena $\mathbf{M}^{1}$, Ravi Teja $\mathrm{A}^{2 *}$ and Vijayakumari $\mathbf{M}^{3}$ \\ ${ }^{1}$ Associate Professor, Osmania Medical College, India \\ ${ }^{2}$ Assistant Professor, Osmania Medical College, India \\ ${ }^{3}$ Professor \& HOD, Department of Radio Diagnosis, India
}

*Corresponding author: Ravi Teja Athkuri, Assistant Professor, Kaloji Narayana Rao University, Osmania Medical College, Hyderabad, Telangana, India, Tel: 9000160610; Email: raviteja_peace@yahoo.com

\section{Research Article \\ Volume 4 Issue 1}

Received Date: January 20, 2020

Published Date: February 03, 2020

DOI: $10.23880 /$ crij-16000163

\section{Abstract}

Introduction: Present day's incidence of dengue increasing becoming the major health problem especially in children under the 5 to 14 years of age. Cross sectional lung imaging becomes one of the priorities in patients of dengue with respiratory difficulty. A Very less literatures available on spectrum of lung involvement in dengue fever in pediatric age group.

Materials and Methods: Observational retrospective study was done among 50 patients positive with dengue fever in a 3 months for a period from August to December 2019 were studied and Spectrum lung involvements are evaluated. Among those 30 patients showed respiratory symptoms.

Results: The commonest chest CT findings were pleural effusion $83.3 \%(n=25)$, ground-glassopacification 53.3\% (n=16), atelectasis $40 \%(n=12)$, patchy consolidation $26.6 \%(n=8)$, air space nodules 3.3\% $(n=1)$, interstitial thickening $13.3 \%(n=4)$ and pericardial effusion $10 \%(n=3)$.

Conclusion: Dengue patients with respiratory difficulty CT chest best choice of investigation. Frequently detected findings on chest CT included pleural effusion, ground-glassopacification and atelectasis.

Keywords: Viral Fever; Pleural Effusion; GGO

Abbreviations: CT: Computed Tomography; ARDS: Acute Respiratory Distress Syndrome; CGO: Ground Glass Opacity; DHF: Dengue Hemorrhagic Fever.

\section{Introduction}

Dengue is the becoming major health problem in children especially in the tropical and sub-tropical regions [1]. In India, as of August 2017, more than 36,635 cases of dengue fever were reported according to figures released by the National Vector-Borne Disease Control Programme. But there is no literature review of number of dengue cases with positive lung involvement and spectrum of involvement in paediatric age group [2].

The pathophysiological features are increased vascular permeability causing dysfunctional bleeding. These mechanisms can explain varied systemic involvement [2]. Dengue virus antigen has been found in alveolar lining cells of the lung [3]. Increased permeability of the alveolar-capillary 
membrane results in oedema in the alveoli and interstitial spaces. Thoracic manifestations such as pleural effusion, pneumonitis, pulmonary haemorrhage and ARDS have been reported in dengue infections [3]. However, there is a paucity of clinical literature detailing CT features of dengue fever in children an Indian context. The authors have attempted to demonstrate the spectrum of CT findings in the thorax in children with dengue fever.

\section{Material and Methods}

Study conducted retrospectively in 50 dengue serologically positive children, among those 30 are suffering from respiratory problems. Helical noncontrast CT exams of chest were obtained standard protocols. The images were reviewed on lung, bone and mediastinal windows $[4,5]$. The presence of 1) Ground glass opacity (GGO), 2) Consolidation, 3) Airspace nodules, 4) Interlobular septal thickening, 5) Effusion, 6) Any cavitations, 7) Any blubs/ bullae, 8) Atelectasis, and 9) Peribronchovascular interstitial thickening were recorded based on the recommendations of the Nomenclature Committee of the Fleischner Society [6].

\section{Statistical Analysis}

The basic statistical analysis was done by SPSS Software The level of significance was estimated with $95 \%$ and confidence interval with 'p' value $<0.05$.

\section{Results}

The study population showed plural effusion was detected in 25 patients. It was bilateral in 7 cases and unilateral (right-sided in 16 and left sided in 2) in 18 cases. Lung parenchymal involvement was bilateral in 9 patients. The most common finding was GGO (10 patients); followed by atelectasis (18), consolidation (8 patients). Airspace nodules and interlobular septal thickening were observed in 4 patients each and pericardial effusion in 3 patients. Pleural effusion was the sole finding in $25 / 30$ patients (Figures 1 \& 2).

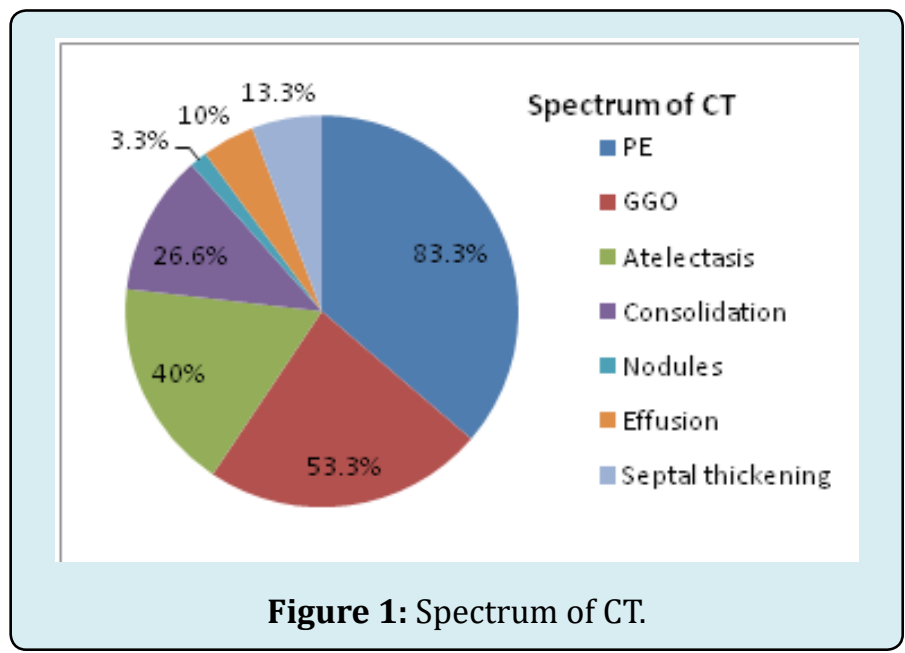

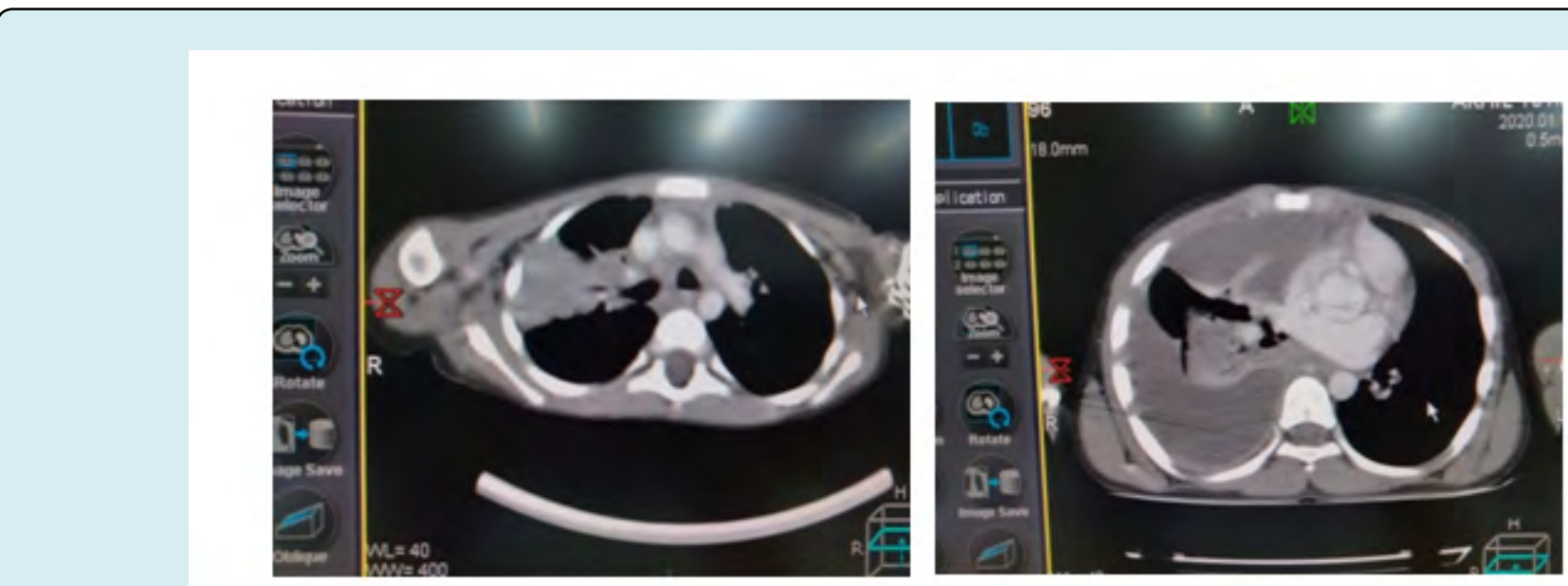

Figure 2: Showing the consolidation and effusion of right lung.

\section{Discussion}

Dengue is a febrile viral disease caused by flavivirus. It is Endemic and threatens the health of $40 \%$ of the world's population and has become a major International Public Health concern in recent years [7]. An estimated 50 million dengue infections occur each year with 5,000,000 cases of
DHF and at least 12,000 deaths annually [8]. In the spectrum of Dengue chest showed following abnormalities in chest. A study conducted by Wang CC, et al. [9] reported that pleural effusion (54.7\%) was the most common abnormal chest radiographic findings in patients with dengue. In our study, pleural effusion $(n=25)$ was the most common chest finding 
in dengue fever. A study of Chinese patients by Tianli $\mathrm{H}$, et al. also reached a similar conclusion. Ground glass opacity (GGO) was the next most common parenchymal finding in the present study [10]. This was in concordance with the study conducted by Rodrigues RS, et al. [7] on lung in dengue. Grosslung changes were not observed even in severe disease in our study [11]. The limitation of this study was the small study population and included only paediatric patients and study was done during epidemic of dengue.

\section{Conclusion}

Dengue is a viral infection with multisytemic involvement affecting a large population worldwide through vector. Dengue pediatric patients suffering respiratory complaints, CT chest useful modality and describes the extent of lung involvement.

\section{References}

1. WHO (1997) Dengue haemorrhagic fever: diagnosis, treatment, prevention and control. $2^{\text {nd }}$ (Edn.),World Health Organisation, Geneva.

2. WHO (2008) Health Situation in South-East Asian Region, 2001-2007. World Health Organisation.

3. Bhatt S, Gething PW, Brady OJ, Messina JP, Farlow AW, et al. (2013) The global distribution and burden of dengue. Nature 496(7446): 504-507.
4. Martina BE, Koraka P, Osterhaus AD (2009) Dengue virus pathogenesis: an integrated view. Clin Microbiol Rev 22(4): 564-581.

5. Jessie K, Fong MY, Devi S, Lam SK, Wong KT (2004) Localization of dengue virus in naturally infected human tissues, by immunohistochemistry and in situ hybridization. J Infect Dis 189(8): 1411-1418.

6. Hansell DM, Bankier AA, MacMahon H, McLoud TC, Müller NL, et al. (2008) Fleischner Society: glossary of terms for thoracic imaging. Radiology 246(3): 697-722.

7. Rodrigues RS, Brum AL, Paes MV, Póvoa TF, Basilio-deOliveira CA, et al. (2014) Lung in dengue: computed tomography findings. PLoS One 9(5): 96313.

8. Sai PMC, Dev B, Krishnan R (2005) Role of ultrasound in dengue fever. Br J Radiol 78(929): 416-418.

9. Wang CC, Wu CC, Liu JW, Lin AS, Liu SF, et al. (2007) Chest radiographic presentation in patients with dengue hemorrhagic Fever. Am J Trop Med Hyg 77(2): 291-296.

10. Mohamed NA, El-Raoof EA, Ibraheem HA (2013) Respiratory manifestations of dengue fever in TaizYemen. Egyptian J Chest Diseases and Tuber 62(2): 319323.

11. WHO (2009) Dengue: guidelines for diagnosis, treatment, prevention, and control. World Health Organization, Geneva. 